\title{
Using thermal tracers to estimate flow velocities of shallow flows: laboratory and field experiments
}

\author{
Rui L.P. de Lima ${ }^{1,3}$, João R.C.B. Abrantes ${ }^{2,3}$, João L.M.P. de Lima ${ }^{2,3^{*}}$, M. Isabel P. de Lima ${ }^{2,3}$ \\ ${ }^{1}$ INDYMO, Molengraaffsingel 12-14, 2629 JD Delft, The Netherlands. \\ ${ }^{2}$ Department of Civil Engineering, Faculty of Science and Technology of the University of Coimbra (DEC-FCTUC), Rua Luís Reis San- \\ tos, Campus II - University of Coimbra, 3030-788 Coimbra, Portugal. \\ ${ }^{3}$ Institute of Marine Research (IMAR) and Marine and Environmental Sciences Centre (MARE), Faculty of Science and Technology of the \\ University of Coimbra, 3004-517 Coimbra, Portugal. \\ ${ }^{*}$ Corresponding author. Tel.: +351.239797183. E-mail: plima@dec.uc.pt
}

\begin{abstract}
Accurate measurement of shallow flows is important for hydraulics, hydrology and water resources management. The objective of this paper is to discuss a technique for shallow flow and overland flow velocity estimation that uses infrared thermography. Laboratory flumes and different bare, vegetated and paved field surfaces were used to test the technique. Results show that shallow flow surface velocities estimated using thermal tracers and infrared technology are similar to estimates obtained using the Acoustic Doppler Velocimeter; similar results were also obtained for overland flow velocity estimates using thermography, here comparing with the dye tracer technique. The thermographic approach revealed some potential as a flow visualization technique, and leaves space for future studies and research.
\end{abstract}

Keywords: Shallow flow velocities; Thermal tracer; Infrared thermography; Flow visualization.

\section{INTRODUCTION}

Most research related to hydraulics and hydrology relies on accurate measurements of flow velocity, in particular shallow flows. These flows can occur in pristine, agricultural and urbanized drainage basins. Their characterization is of interest for e.g. water quality, water storage characterization and hillslope hydrology studies.

Open flow velocity is inherently difficult to measure, as it may vary in time and space. In addition, measurement instruments have to deal with problems such as variability of channel bed conditions, presence of sediments, accretion and erosion problems, tidal effects, confluence of water masses, or even the presence of vegetation or air-entrainment. All of these factors contribute to inaccurate measurements and complicate the important task of quantifying the flow and velocity fields. For overland flow conditions, the limited water depths create even more difficulties to evaluate flow velocities.

Significant improvements and developments in sensoring equipment and technologies were accomplished in the last decades. This resulted in a wide spectrum of powerful and versatile options for flow velocity measurements, which offer notable capabilities and high accuracy data. However, flow measurement devices may reveal some limitations when operating outside their ideal measurement conditions. In particular for shallow flow and overland flow, the characterization of the velocity fields is complicated, mostly due to its low depths, which restricts the use of many flow measuring devices.

For a long time, lower accuracy techniques used in shallow flow velocity measurements were based on the determination of the travel time of a tracer across a defined section, in both laboratory (e.g. Abrahams and Atkinson, 1993; Giménez and Govers, 2002) and field conditions (e.g. Horton et al., 1934; Wirtz et al., 2012). In this approach, the quality of the visualization of the tracers added to the flow is crucial for the success of the measurement. Several substances have been tested as tracers in flow velocity experiments. The most commonly used in shallow water flows are dyes of different colours, fluorescent dyes (e.g. Zhang et al., 2010), fluorescent particles (e.g. Tauro et al., 2012), or electrolytes (e.g. Lei et al., 2010).

Infrared (IR) thermography is an effective, fast and accurate method of monitoring temperature gradients (spatial and temporal). It has become a consolidated technique for uses in military and law enforcement applications (night vision), research, industry, building inspections and electrical systems diagnosis. Due to the recent reduction of costs of thermal cameras along with the increased portability and resolution, its applications in water resources, hydrology and soil and water preservation have been developing significantly. Some applications include large scale aerial thermal scans (e.g. Rayne and Henderson, 2004), search for groundwater inflows (e.g. Schuetz and Weiler, 2011) and karst hydrogeology (e.g. Campbell et al., 1996).

The use of IR thermography for quantitative flow measurements has not been extensively explored so far and its capabilities have yet to be studied. However, some successful examples can already be found in the literature:

i. Chung and Grigoropoulos (2003) and Liu et al. (2005) presented a technique for velocity measurements in microfluidic silicon devices, where most flow meters are not adequate because of its small dimensions. In this technique, the fluid is heated by a pulsed infrared laser beam (relies on the fact that silicon is transparent for infrared wave lengths), and the heat gradients are monitored through thermography.

ii. In a wide open flow flume, Liang et al. (2012) studied the feasibility of using thermography to visualize turbulent mixing processes in shallow flows. The hot water is injected behind a cylinder, which originates turbulent structures (wake and vortices), visible through thermography.

iii. Applied in the field to wetlands, Schuetz et al. (2012) presented a technique to study solute transport processes involving slug hot water addition to the flow and infrared thermography. Mean flow velocity, dispersion and dominating flow paths could also be remotely detected in this work. It dealt with low flow velocities and the heat tracer cooling effects were analysed (advection, dispersion and conduction). 
iv. In the laboratory, de Lima and Abrantes (2014b) used thermal tracers to visualize shallow flows and to estimate overland and rill flow velocities and compared the traditional dye tracer technique with this thermal tracer technique. The research included several laboratory studies showing that infrared thermography can be used to assess different surface hydrologic processes; e.g. estimate soil surface microrelief and rill morphology (de Lima and Abrantes, 2014a), map soil surface permeability (de Lima et al., 2014b), soil surface macroporosity (de Lima et al., 2014a) and raindrop size distributions (de Lima et al., 2015).

The objective of this paper is to discuss a versatile technique based on infrared thermography to estimate shallow and overland flow velocities. This will be sustained with an overview of laboratory and field experiments using this technique, where promising results were achieved.

\section{MATERIAL AND METHODS}

The technique here presented uses infrared thermography imaging systems (e.g. infrared video cameras) for the visualization and quantification of the motion of a heated fluid (e.g. hot water) - a thermal tracer - added to the flow, consequently enabling flow surface velocity estimation.

It is a two dimensional technique, where the resulting thermal videos of the flow surface, obtained with infrared cameras, are sequences of greyscale or colour scale images (i.e. thermograms) where higher temperatures are usually represented by brighter colours and lower temperatures by darker colours. The thermal tracer added to the flow is clearly visible in the thermograms as a bright stain, allowing downstream movement to be studied. The surface flow velocity can be computed by measuring the travel time of the thermal tracer added to the flow during its passage over a defined measuring section.

\section{Laboratory and field setups}

The thermal tracer technique was tested in two different laboratory setups, and in the field (different surfaces).

Laboratory experiments were performed in i) shallow flow conditions (water depths between $0.05-0.10 \mathrm{~m}$ ), using an impermeable flume, and ii) overland flow conditions (water depths lower than $0.01 \mathrm{~m}$ ), using a soil flume. In all the setups, an infrared camera was hanged above the flume, recording the flow. Additional equipment was used for each specific setup (e.g. ADV, regular video camera), as will be described in the thermal technique validation section.

For the shallow flow experiments (de Lima, 2013; de Lima et al., 2014c), a $4.5 \mathrm{~m}$ long and $0.3 \mathrm{~m}$ wide multipurpose demonstration flume was used (Fig. 1). The flume bed and walls are made of plexiglass acrylic sheets, with leak proof joints, thus impermeable, smooth and transparent. The set-up allows a motorized adjustment of the bed slope and the use of a downstream tailgate for flow depth control. The flume operates as a self-recirculation circuit with integrated pumps and the water flow is controlled by valves.

The overland flow experiments in the laboratory (e.g. de Lima and Abrantes, 2014b) were conducted using a $3.0 \mathrm{~m}$ long and $0.3 \mathrm{~m}$ wide soil flume, adjusted at $10 \%$ slope (Fig. 2); the soil surface was a uniformly smooth plane, without any rough protuberances or other microtopographic elements. The soil used in the experiments was a sandy loam (collected from the right banks of River Mondego, in Coimbra, Portugal; details are given in de Lima et al., 2003; Montenegro et al., 2013); the soil layer had a depth of $0.10 \mathrm{~m}$. A water supply system, comprising a constant head tank and a feeder tank, was installed at the upstream end of the soil flume and generated a constant flow.

The field experiments were conducted in different conditions: bare soil, vegetated soil surfaces (e.g. surfaces covered with grass or tree leafs), and paved surfaces (e.g. asphalt pavements, concrete sidewalks). The field experiments were conducted in the surrounding areas of the Department of Civil Engineering of the Faculty of Sciences and Technology of the University of Coimbra, in Portugal.

\section{Thermal imaging systems}

Two portable infrared video cameras were used in the experiments: i) A FLIR PathFinderIR-LE in the laboratory shallow flow experiments; and ii) An Optris PI-160 in both the laboratory and field overland flow experiments. Specifications of both cameras are presented in Table 1. The infrared video cameras were positioned above the target surface (flumes and field surfaces), guaranteeing a good coverage of the measuring sections (Figs. 1 and 2).

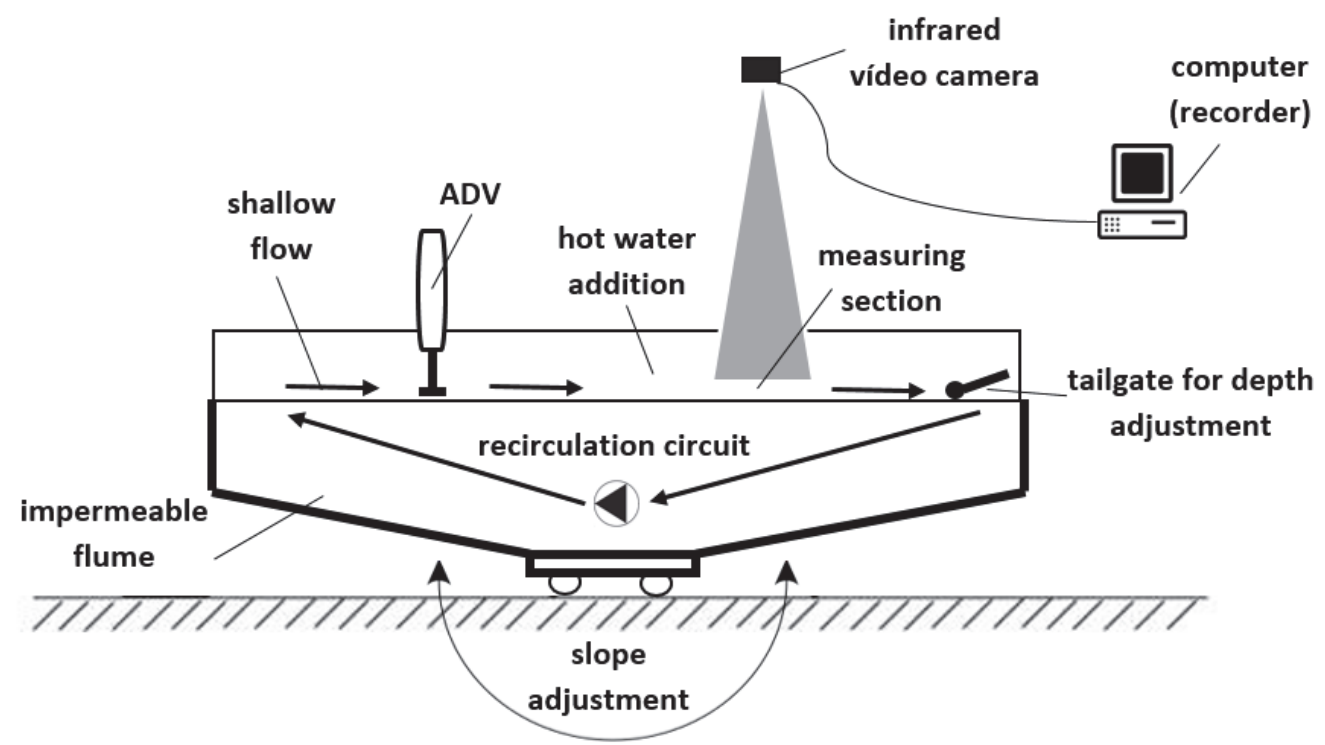

Fig. 1. Schematic representation of the laboratory set-up used in the shallow flow experiments, with an impermeable flume (adapted from de Lima, 2013). 


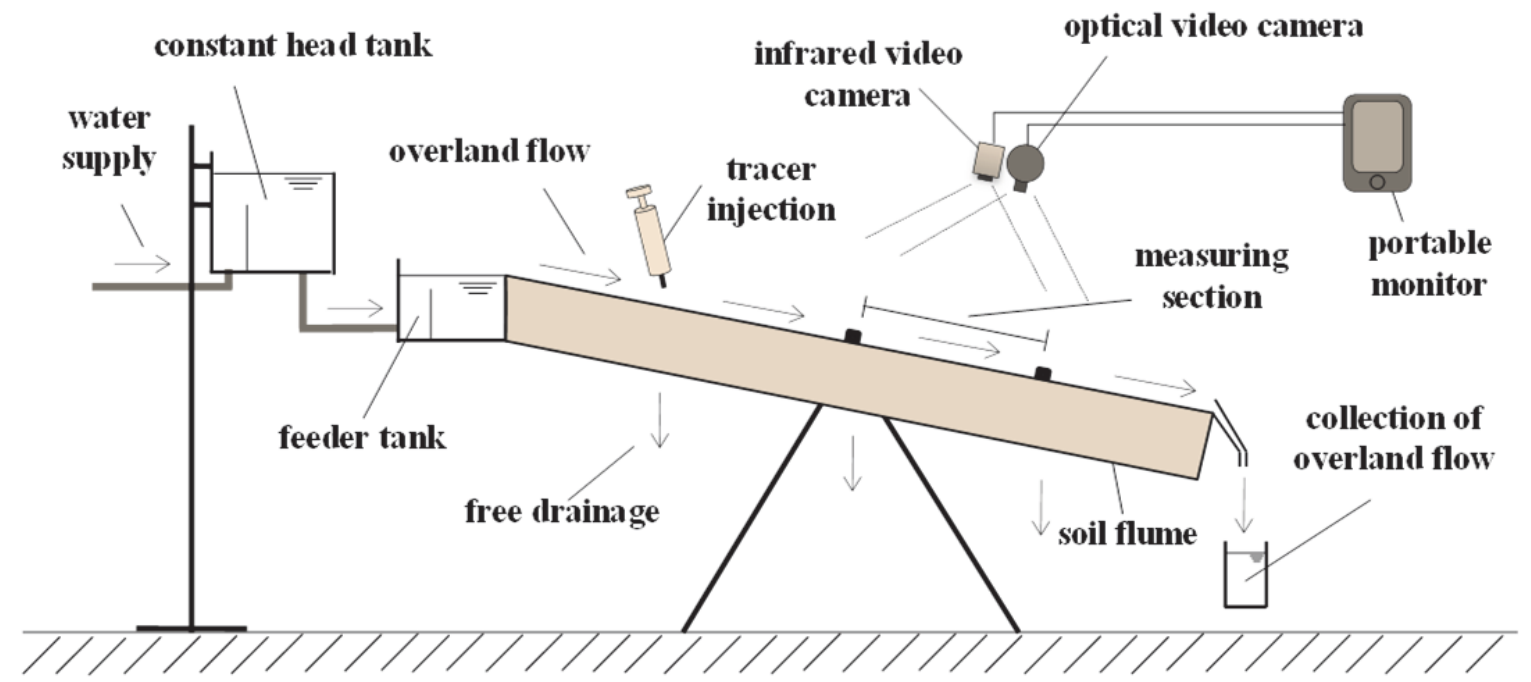

Fig 2. Schematic representation of the laboratory set-up used in the overland flow experiments, including a soil flume.

Table 1. Infrared video cameras' basic specifications.

\begin{tabular}{llll}
\hline \multirow{2}{*}{ Specification } & \multirow{2}{*}{ Unit } & \multicolumn{2}{c}{ Infrared camera } \\
\cline { 3 - 4 } & & FLIR PathFinderIR-LE* & Optris PI-160** \\
\hline Optical resolution & Pixel & $320 \times 240$ & $160 \times 120$ \\
Field of view (FOV) & ${ }^{\circ}$ & $36 \times 27$ & $23 \times 17$ \\
Focal length & $\mathrm{mm}$ & 19 & 10 \\
Frame rate & $\mathrm{Hz}$ & 30 & 120 \\
Operating temperature & ${ }^{\circ} \mathrm{C}$ & $-40-80$ & $-20-100$ \\
Thermal sensitivity & $\mathrm{mK}$ & 100 & 80 \\
Spectral range & $\mu \mathrm{m}$ & $8.0-14.0$ & $7.5-13.0$ \\
Weight & $\mathrm{kg}$ & 0.400 & 0.250 \\
Dimensions & $\mathrm{mm}$ & $58 \times 57 \times 72$ & $45 \times 45 \times 62$ \\
Price (2014) & $\mathrm{USD}$ & $\sim 2300$ & $\sim 3300$ \\
\hline
\end{tabular}

* Used for the shallow flow measurements;

** Used for the overland flow measurements.

\section{Experimental procedure}

In all experiments, different volumes of heated tracers were added to the flow and different flow discharge rates and flow depths were studied. Moreover, in the shallow flow experiments conducted in the laboratory impermeable flume, different slopes were considered; for the soil flume overland flow tests, the surface slope was fixed at $10 \%$.

The thermal tracers (e.g. hot water, $\sim 80^{\circ} \mathrm{C}$, heated using an electric kettle), at temperatures considerably higher than the average water surface temperatures, were manually added to the flow using cups and syringes; care was taken not to disturb the surface of the flowing water. Although increasing the temperature of the water changes its properties (e.g. density, viscosity), the use of heat tracers are only applied locally and the quantity of added water is low when compared with the flow discharges used. Therefore, this has little influence in the overall flow velocity, and may even be beneficial since the heat tracers would remain at the surface, enhancing thermal visualization.

Thermal video images of the flow surface, recorded with the infrared video cameras, were analysed using computer software. Flow velocities were estimated by measuring the travel time of the thermal tracer during its passage over the measuring sections.

\section{Validation of thermal technique}

In order to validate the thermal tracer technique, two other flow velocity measurement techniques were used for comparison: i) in the laboratory impermeable flume, the shallow flow experiments were monitored simultaneously with an Acoustic Doppler Velocimeter (ADV); and ii) in the overland flow experiments, both in the laboratory and in the field, the velocity estimate was compared with results from the traditional dye tracer technique.

Acoustic Doppler Velocimeter is a well-established and trustworthy velocity measurement device. For this study, A SonTek 16-MHz Micro ADV was installed upstream of the measuring section. A 2D side-looking probe was used, since it is the most adequate probe when dealing with shallow flow depths. For each flow condition tested, the average flow velocity was computed from 600 samples (obtained using SonTek software). The air bubbles originated by the turbulence of the water flow were sufficient to reflect the acoustic signals, allowing the ADV to properly detect and compute velocity.

In the overland flow velocity experiments, in order to allow the simultaneous application of the thermal and dye tracer technique, a combined dye-thermal tracer was used. This tracer comprised simultaneously dye and thermal characteristic (e.g. 
blue litmus tracer diluted in hot water). For this purpose, an optical video camera (regular video) was positioned side by side with the thermal video camera (Table 1), providing simultaneous real image and thermal images. The optical camera (Logitech QuickCam E 3500 Plus) had a digital resolution of $320 \times 240$ pixels and a frame rate of $15 \mathrm{~Hz}$.

\section{RESULTS}

The multiple laboratory and field setups used allowed to test the thermal velocity estimation method for several flow conditions, such as different slopes (shallow flow experiments), water depths, flow velocities/discharges, types of surfaces (impermeable flume vs soil flume vs field) or presence of vegetation and sediments (field tests).

During this study, several variations regarding the procedures of the presented thermal technique were performed, namely variation of the quantity of water added to the flow, or the addition of heat tracer at different distances upstream. Some results from these exploratory experiments will be presented below, for each different setup.

\section{Shallow flow - laboratory experiments}

Figure 3 shows a compilation of all the average flow velocities and corresponding standard deviations obtained using the IR technique, compared to the values obtained using an $\mathrm{ADV}$, for a set of experiments comprehending various slopes and water flow depths. It was observed that the flow velocity standard deviation values are relatively low, fluctuating between 4.1 and $18.4 \mathrm{~mm} / \mathrm{s}$ for velocities between $80 \mathrm{~mm} / \mathrm{s}$ and $200 \mathrm{~mm} / \mathrm{s}$. This suggests that the IR technique performed well for the multiple tested conditions. Nevertheless, most flow velocities obtained by this technique are overestimated when compared to the reference values from the ADV (check data against the 1:1 reference line in Fig. 3). This can be explained by the influence of the thermal tracer method on flow conditions and the ADV location. The ADV measurements are taken for undisturbed flow, i.e. upstream of the cross section where the hot water was added to the flow, which clearly affects flow conditions; the addition of the tracer to the flow increases locally the flow velocity in spite of the care to pour the hot water slowly and carefully on the flow to minimize disturbance. This discrepancy between the velocities measured by the two techniques could also be explained by the position of the ADV probe on the flow. The vertical flow velocity profile is not uniform and thus the data from the ADV can slightly differ from surface velocities, which are captured by the thermal technique. The linear fit shown in Fig. 3 also revealed a tendency to overestimate more for lower flow velocities (water is more responsive to disturbance).

In order to study the effect of the volume of hot water added to the flow in the final velocity results, experiments were made using three different added volumes $(87.5,175.0$ and $350.0 \mathrm{ml})$, for three different flow velocities. Figure 4 suggests that the method is less precise for lower velocities. In addition, higher quantities of added water may increase the overestimation of flow velocities, which is more prominent for low velocities. This effect was to be expected because this method is invasive and can alter flow conditions (discharge and velocity), depending on the amount of water added.

In most experiments, water was added to the flow near the upstream edge of the monitored area of the water surface. However, experiments were also made adding hot water at different distances upstream. Figure 5 shows results from those experimental tests: in comparison to the ADV reference values

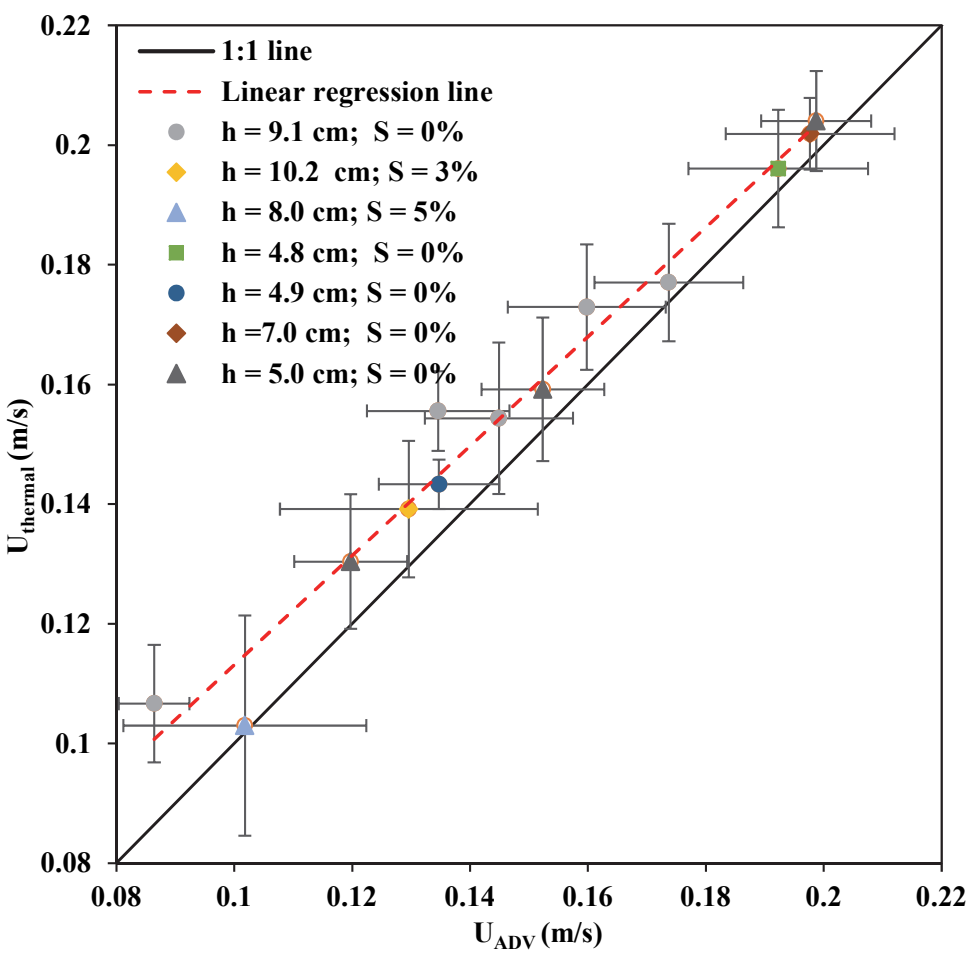

Fig. 3. Overview of the results from the shallow flow experiments (impermeable flumes). The velocities obtained with the thermal tracer technique $\left(\mathrm{U}_{\text {thermal }}\right)$ is compared to the values measured with an $A D V\left(U_{A D V}\right)$, for different flow depths $(h)$ and slopes $(S)$. Each point represents a mean value from 6-9 repetitions of the procedure (volume of $175 \mathrm{ml}$ of heat tracer added to the flow). The 1:1 reference line and linear fit to the data are shown. 


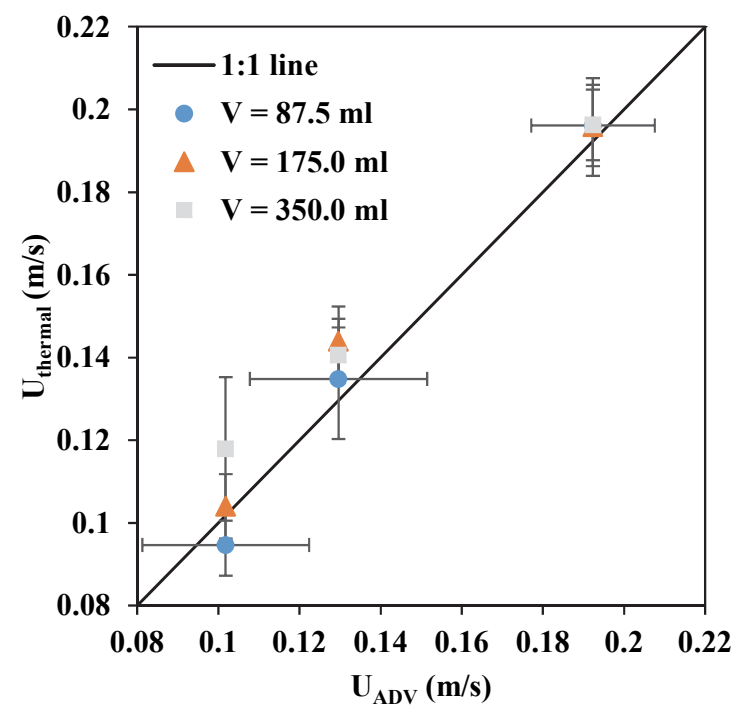

Fig. 4. Representation of the effects of the addition of different volumes (V) of thermal tracer (hot water) to the flow, in the shallow flow experiments. Measurements from the two techniques are compared: thermal tracer $\left(\mathrm{U}_{\text {thermal }}\right)$, and $\mathrm{ADV}\left(\mathrm{U}_{\mathrm{ADV}}\right)$. The $\mathrm{ADV}$ measurements are taken upstream the section where the tracer is added to the flow, thus remain unaffected. Experiments were undertaken within the slope range of $0-5 \%$ and depth range of $0.05-0.10 \mathrm{~m}$. Each point represents a mean value from 6-9 repetitions of the procedure.

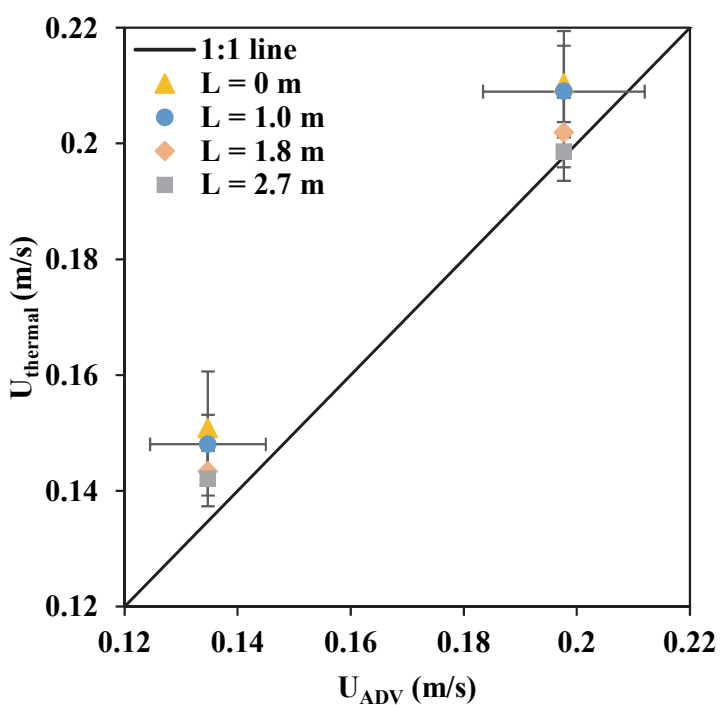

Fig. 5. Comparison between shallow flow velocities in the impermeable flume, estimated using the thermal tracer technique $\left(\mathrm{U}_{\text {thermal }}\right)$ and the ADV $\left(\mathrm{U}_{\mathrm{ADV}}\right)$. The thermographic estimates were obtained for adding the tracer at different distances upstream of the monitored water surface area (L). The ADV measurements are taken upstream the section where the tracer is added to the flow, thus remain unaffected. Each point represents a mean value from 6-9 repetitions of the procedure (volume of $175 \mathrm{ml}$ of heat tracer added to the flow).
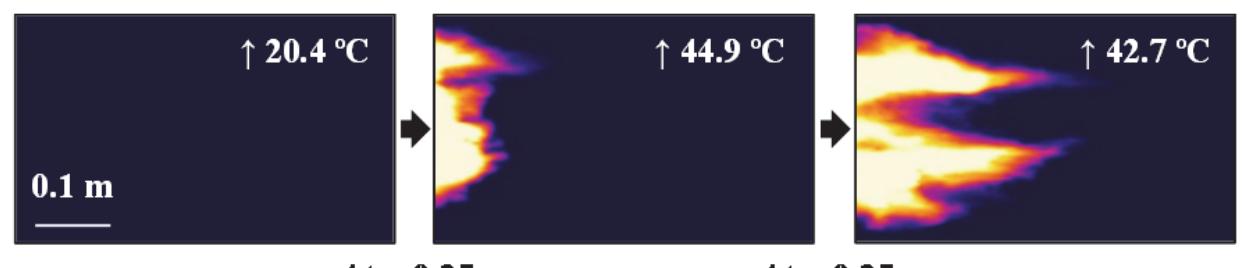

$\Delta \mathbf{t}=\mathbf{0 . 2 5} \mathrm{s}$

$\Delta \mathbf{t}=\mathbf{0 . 2 5} \mathrm{s}$
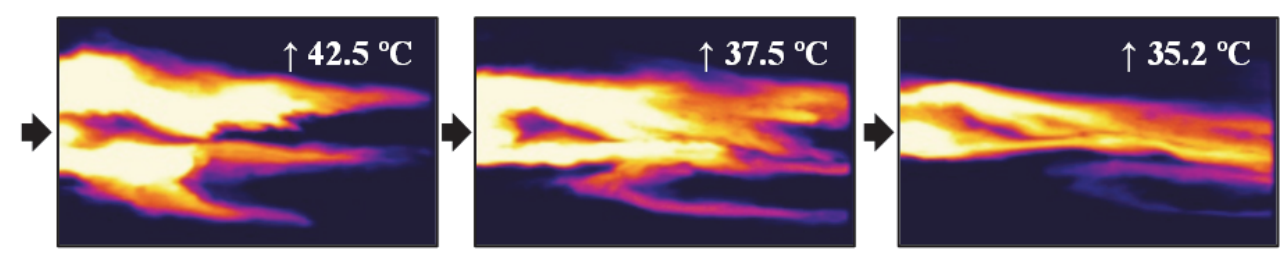

$\Delta t=0.25 \mathrm{~s}$

$\Delta t=0.25 s$

$\Delta \mathbf{t}=\mathbf{0 . 5 0} \mathrm{s}$
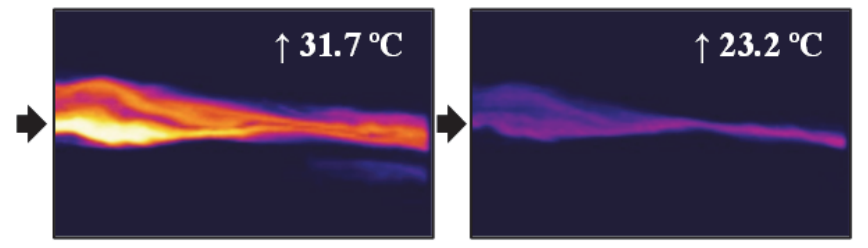

Temperature, $\mathrm{T}\left({ }^{\circ} \mathrm{C}\right)$

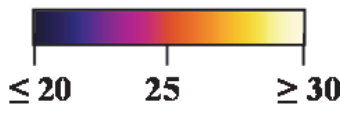

$\Delta \mathbf{t}=\mathbf{0 . 5 0} \mathrm{s}$

$\Delta t=1.50 \mathrm{~s}$

Fig. 6. Chronological sequence of thermal video snapshots of the monitored area of the soil surface, in the overland flow experiments conducted in the soil flume, for a flow discharge of $256 \mathrm{ml} / \mathrm{s}$ and a volume of $20 \mathrm{ml}$ of heated tracer added to the flow. Maximum detected temperatures are identified in every thermal snapshot.

for flow velocity, the overestimate of the flow velocity by the thermal technique (caused by adding water to the flow) decreases as the water is introduced further upstream from the monitored area. This can be explained by considering that the disturbance of the flow originated when adding the hot water has more time to get dissipated when the water is added further upstream; thus, the hot water has more time to fully acquire the "real" surface flow velocity, which allows for more accurate results of the IR approach to flow (surface) velocity estimates. 


\section{Overland flow - laboratory experiments}

To estimate flow velocities and compare the two tracer techniques - thermal and dye -, real image and thermal videos were analyzed separately; a "combined" tracer was used, as explained earlier. Flow velocities were estimated by measuring the travel time of the leading edge of the injected tracer during its passage over the monitored area of the water surface, by evaluating both the real image and the thermal video snapshots (Fig. 6). The tracer is clearly visible in the thermal videos. The tracer leading edge movement is normally better defined and better shaped in thermal images than in real images, which analysis may require sharpening and highlighting using image analysis tools. However, the thermal mark of the injected tracer remains visible for some additional seconds after the passing of the tracer, due to the heating of the soil surface. In the real image videos, the residual dye mark is less evident. Moreover, in the experiments with higher water depths (shallow flow experiments), this effect was not visible, as the bright heat stain fades fast.

Both the dye and thermal techniques yielded similar results for all flow discharges used, as shown in Fig. 7. The overland flow surface velocities estimated by the two techniques - based on using a dye tracer and a thermal tracer - showed good correlation, with a coefficient of determination $\left(\mathrm{R}^{2}\right)$ of 0.997 and a linear fit almost coincident to the 1:1 reference line.

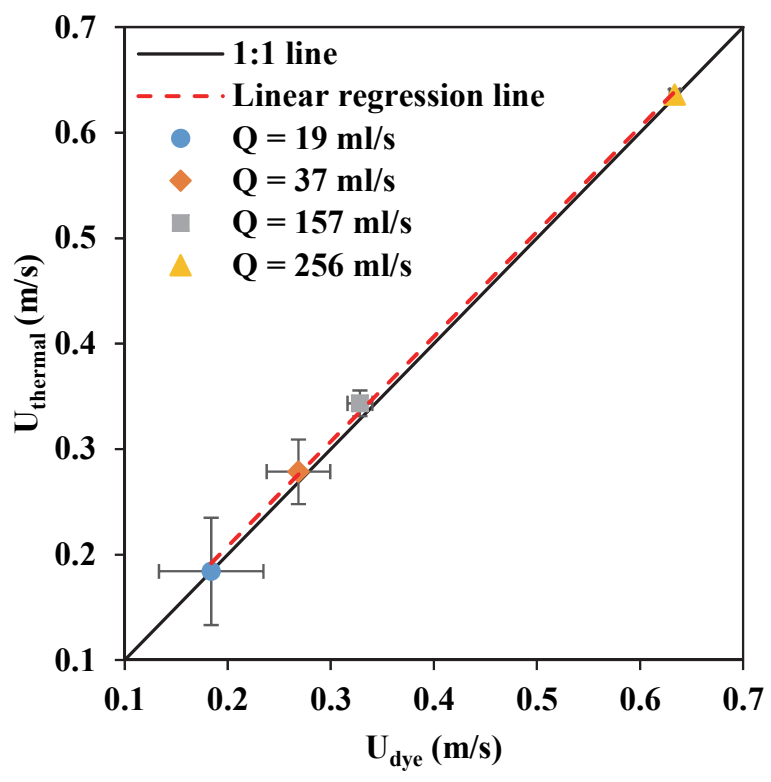

Fig. 7. Comparison between overland flow velocities measured in the soil flume, using the thermal tracer technique $\left(\mathrm{U}_{\text {thermal }}\right)$ and the dye tracer technique $\left(U_{\text {dye }}\right)$, for different flow rate discharges $(Q)$, ranging from 19-256 ml/s. The volume of heated tracer added to the flow ranged between 7-25 ml. Each point represents a mean value from 3 repetitions of the procedure. 1:1 reference line and linear fit to the data are plotted.

In the video imagery analysis, timing errors are unavoidable due to the frame rate of the recording system. These errors increase with flow velocity, especially when using short flow path lengths for the tracer measurements, and are expected to increase the uncertainty in velocity estimates. Nevertheless, surface velocities are assessed using the approaches investigated in this work (not mean flow velocities in a given cross section). But for many applications the surface velocity estimate might be nevertheless useful and the approximation to the mean velocity enough when applying appropriate correction factors.

Similarly to the results obtained for the shallow flow experiments, results from the overland flow tests also showed that using larger volumes of tracer leads to higher flow velocities, and therefore indicating an overestimation of the "real" flow velocity. This is clearly more relevant for low flows (in our flume experiments, caused by smaller discharges upstream) because in those conditions the influence of the volume of injected tracer on the flow is more noticeable. The "optimal" volume of tracer is therefore the smallest amount that permits the application of the technique, i.e. clear visualization of the leading edge movement, although this amount varies with flow conditions.

\section{Overland flow - field experiments}

The results of the application of the thermal tracer technique in the field, for different surfaces, can be seen in Fig. 8; a combined tracer is also used here. In Fig. 8, pairs of thermal images and pairs real images of the same monitored area (each set of two images show the monitored area just before and during the passage of the tracer) are shown side by side for comparison; the figure shows field tests on different surfaces, including bare soil, mulched surfaces and paved surfaces.

On vegetated surfaces, in particular when small volumes of tracer were used, often it was only possible to estimate the flow velocity with the thermal tracer technique because the dye tracer was not perceptible (hidden below leaves and mulch).

The comparison between the flow velocities estimated using the dye tracer and the thermal tracer technique is shown in Fig. 9; results present a good correlation, with a coefficient of determination $\left(\mathrm{R}^{2}\right)$ of 0.997 and a linear fit almost coincident to the 1:1 reference line. However, Fig. 9 only includes data from surfaces without vegetation or mulching because for these cases the dye tracer estimates of the flow velocities were not possible to obtain, as explained above. For the other surfaces (e.g. concrete block pavements, asphalt surfaces, bare soil), the progress of the tracer movement with the flow is clearly observed, both in the thermal and real images.

\section{CONCLUSIONS}

Results show that thermal tracers can be used to estimate small scale shallow flow space-averaged velocities, since results are similar to those resulting from other traditional and well established flow velocity measurement techniques. Thermal tracers showed potential for both laboratory and field applications.

In the shallow flow experiments, the IR based technique performed well for multiple slope and water depth conditions, under the experimental settings used. For overland flow velocity measurements, results obtained from both laboratory and field tests show that, in comparison to the dye tracer technique, the main advantage of using thermography is the higher visibility of the leading edge of the thermal mark. This is more prominent in field conditions, where vegetation or mulch can impede dye tracing.

Thermography is particularly useful when dealing with very shallow water depths, where the current available options have many limitations, often challenged by minimum working depths of equipment, or other unfavourable conditions. The inexistence of constraints regarding the use of thermography in the presence of sediments (muddy flows), debris or rocks is another advantage (usually also a limitation for other methods). 

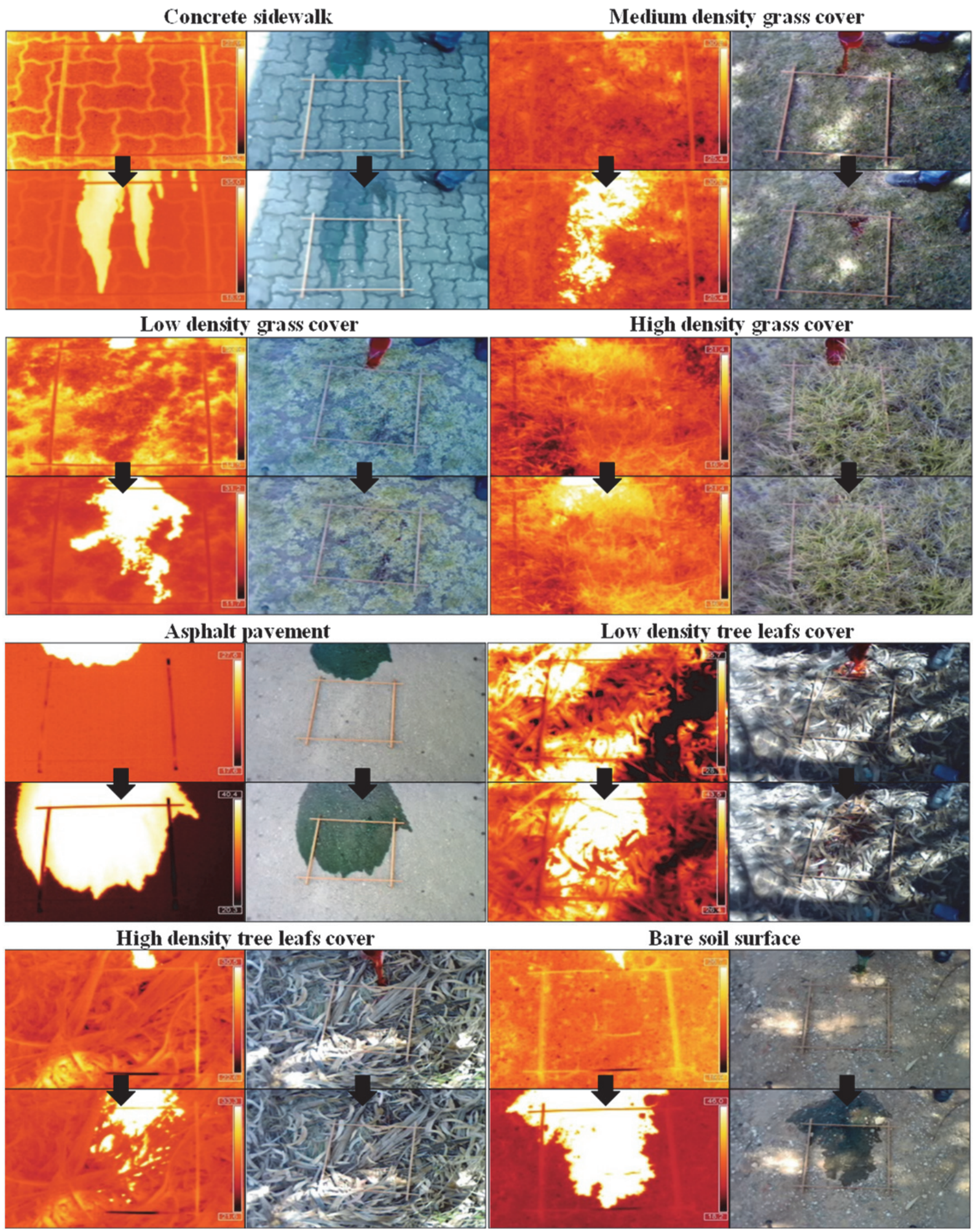

Fig. 8. Real image and thermal video snapshots taken during the experiments conducted in the field, for estimating overland flow velocities over different surfaces. A combined dye-thermal tracer is used, and the image pairs allow comparing the visualization of the passage of the tracer thought a given monitored area. For the vegetated surfaces, the presence of the (dye) tracer in the real image snapshots is not visible. 


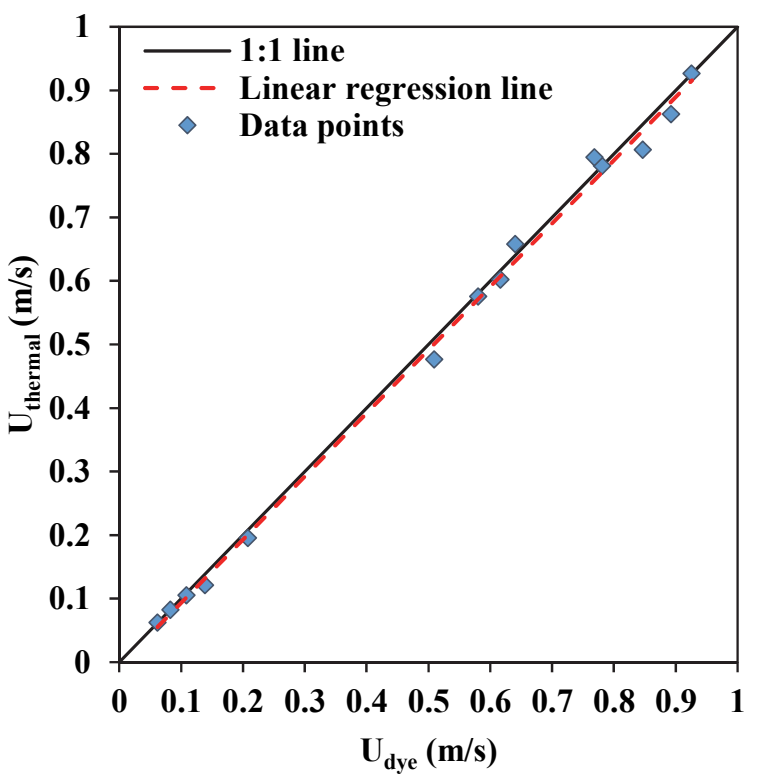

Fig. 9. Comparison between overland flow velocities measured in different field surfaces, using the thermal tracer technique $\left(U_{\text {thermal }}\right)$ and the dye tracer technique $\left(\mathrm{U}_{\mathrm{dye}}\right)$. Each data point represents one repetition of the experimental procedure in a different surface. The 1:1 reference line and the linear regression fit to the data points were plotted.

Acknowledgements. The authors wish to thank Theodore G. Cleveland, for the use of the impermeable flume when the first author was at the Department of Civil \& Environmental Engineering of the Texas Tech University, USA.

\section{REFERENCES}

Abrahams, A.D., Atkinson, J.F., 1993. Relation between grain velocity and sediment concentration in overland flow. Water Resour. Res., 29, 3021-3028.

Campbell, C.W., Latif, M.A., Foster, J.W., 1996. Application of thermography to Karst hydrology. J. Cave Karst Studies, 58, 163-167.

Chung, J., Grigoropoulos, C.P., 2003. Infrared thermal velocimetry in MEMS-based fluidic devices. J. Microelectromech. S., 12, 365-372.

de Lima, R.L.P., 2013. Development of a method using infrared thermography for shallow flow visualization and quantitative estimation of velocity. M.Sc. Dissertation in Civil Engineering, University of Coimbra, Coimbra, Portugal, $77 \mathrm{p}$.

de Lima, J.L.M.P., Abrantes, J.R.C.B., 2014a. Can infrared thermography be used to estimate soil surface microrelief and rill morphology? Catena, 113, 314-322.

de Lima, J.L.M.P., Abrantes, J.R.C.B., 2014b. Using a thermal tracer to estimate overland and rill flow velocities. Earth Surf. Proc. Land., 39, 1293-1300.

de Lima, J.L.M.P., Singh, V.P., de Lima, M.I.P., 2003. The influence of storm movement on water erosion: storm direction and velocity effects. Catena, 52, 39-56.

de Lima, J.L.M.P., Abrantes, J.R.C.B., Silva Jr., V.P., de Lima, M.I.P., Montenegro, A.A.A., 2014a. Mapping soil surface macropores using infrared thermography: Exploratory laboratory study. Sci. World J., 2014, Article ID 845460, 8 p. de Lima, J.L.M.P., Abrantes, J.R.C.B., Silva Jr., V.P., Montenegro, A.A.A., 2014b. Prediction of skin surface soil permeability by infrared thermography: a soil flume experiment. Quant. Infrared Thermogr. J., 11, 161-169.

de Lima, R.L.P., Cleveland, T.G., Carvalho, R.F., 2014c. Using infrared thermography for shallow flow visualization and quantitative estimation of velocity. In: Proceedings of the 3rd IAHR Europe Congress, 14-16 April 2014, Porto, Portugal, $9 \mathrm{p}$.

de Lima, J.L.M.P., Silva Jr., V.P., de Lima, M.I.P., Abrantes, J.R.C.B., Montenegro, A.A.A., 2015. Revisiting simple methods to estimate drop size distributions: a novel approach based on infrared thermography. J. Hydrol. Hydromech., 63, 220-227.

Giménez, R., Govers, G., 2002. Flow detachment by concentrated flow on smooth and irregular beds. Soil Sci. Soc. Am. J., 66, 1475-1483.

Horton, R.E., Leach, H.R., Vliet, V.R., 1934. Laminar sheet flow. Trans. Am. Geophys. Union, 15, 393-404.

Lei, T., Chuo, R., Zhao, J., Shi, X., Liu, L., 2010. An improved method for shallow water flow velocity measurement with practical electrolyte inputs. J. Hydrol., 390, 45-56.

Liang, D., Chen, J.M., Chong, K.J.Y., McCorkell, C., 2012. Thermal imaging study of temperature fields in shallow flows. Measurement, 45, 1015-1022.

Liu, D., Garimella, S.V., Wereley, S., 2005. Infrared microparticle image velocimetry in silicon-based microdevices. Exp. Fluids, 38, 385-392.

Montenegro, A.A.A., Abrantes, J.R.C.B., de Lima, J.L.M.P., Singh, V.P., Santos, T.E.M., 2013. Impact of mulching on soil and water dynamics under intermittent simulated rainfall. Catena, 109, 139-149.

Rayne, S., Henderson, G.S., 2004. Airborne thermal infrared remote sensing of stream and riparian temperatures in the Nicola River watershed, British Columbia, Canada. J. Environ. Hydrol., 14, 1-11.

Schuetz, T., Weiler, M., 2011. Quantification of localized groundwater inflow into streams using ground-based infrared thermography. Geophys. Res. Lett., 38, Article ID L03401, $5 \mathrm{p}$.

Schuetz, T., Weiler, M., Lange, J., Stoelzle, M., 2012. Twodimensional assessment of solute transport in shallow waters with thermal imaging and heated water. Adv. Water Resour., $43,67-75$.

Tauro, F., Grimaldi, S., Petroselli, A., Rulli, C., Porfiri, M., 2012. Fluorescent particle tracers in surface hydrology: a proof of concept in a semi-natural hillslope. Hydrol. Earth Syst. Sci., 16, 2973-2983.

Wirtz, S., Seeger, M., Ries, J.B., 2012. Field experiments for understanding and quantification of rill erosion process. Catena, 91, 21-34.

Zhang, G.H., Luo, R.T., Cao, Y., Shen, R.C., Zhang, X.C., 2010. Correction factor to dye-measured flow velocity under varying water and sediment discharges. J. Hydrol., 389, 205213.

Received 16 December 2014 Accepted 1 April 2015 